\title{
Composição florística, diversidade e estrutura da vegetação arbóreo-arbustiva de caatinga sob sistemas silviculturais
}

\author{
Marcelo Silva de LUCENA ${ }^{1 *}$, Allyson Rocha ALVES ${ }^{1,2}$, Ivonete Alves BAKKE ${ }^{1}$ \\ ${ }^{1}$ PPG em Ciências Florestais, Universidade Federal de Campina Grande, Patos, Paraíba, Brasil. \\ ${ }^{2}$ Centro de Ciências Agrárias, Universidade Federal Rural do Semi-Árido, Mossoró, Rio Grande do Norte, Brasil. \\ *E-mail: marceloslucenarn@gmail.com
}

Recebido em dezembro/2017; Aceito em maio/2018.

\begin{abstract}
RESUMO: O presente artigo visou investigar a composição florística, diversidade e parâmetros estruturais proporcionados por quatro sistemas silviculturais à vegetação arbóreo-arbustiva de Caatinga em dois locais contíguos. Um deles está localizado na Estação Ecológica do Seridó (EES); o outro na Fazenda Pedro Cândido (FPC); os dois situados em Serra Negra do Norte-RN. Os sistemas silviculturais foram: corte raso; corte seletivo (diâmetro na base - DNB $>8 \mathrm{~cm}$ ); corte raso com queima dos resíduos da colheita; corte raso com queima dos resíduos da colheita e destoca do caule. Mediu-se em cada área 16 parcelas, com inclusão de indivíduos com $\mathrm{CAP}>6 \mathrm{~cm}$. Determinou-se: composição florística, riqueza de espécies, diversidade, densidade de fustes, dominância absoluta, IP e IMA (1989-2016). Comparou-se a diversidade (J') pelo teste de Tukey $(\mathrm{P}<0,05)$. A riqueza de espécies apresentou condições semelhantes às da época da instalação do experimento. A grande abundância de algumas espécies contribuiu para a redução da diversidade medida pelo Índice de ShannonWeaver, em relação a 1989. Os incrementos proporcionados pelos sistemas silviculturais variaram conforme a área, com tendência de redução do ritmo de crescimento em ambas. O tempo de regeneração (27 anos) não foi suficiente para a restauração integral da dominância absoluta.
\end{abstract}

Palavras-chave: estrutura florestal, restauração florestal, regeneração natural, semiárido.

\section{Floristic composition, diversity and structure of shrub-arboreal vegetation of caatinga under silvicultural systems}

\begin{abstract}
This work aimed to investigate the floristic composition, the diversity and structural parameters provided by four silvicultural systems to arboreal-shrub vegetation in two areas Caatinga. The first area is in the Seridó Ecological Station (SES) and the second is on Pedro Cândido Farm (PCF), in the county of Serra Negra do Norte-RN. The silvicultural systems used were: general cut; selective cut of individuals with base circumference $>8 \mathrm{~cm}$; general cut of all individuals and subsequent burning of crop residues; general cut with subsequent burning of crop residues and removal of stem from soil. It was determined: floristic composition, species richness, diversity, density of stems, absolute dominance, periodic increase and average annual increment (1989-2016). The diversity ( $\left.\mathrm{J}^{\prime}\right)$ was compared by Tukey's test $(\mathrm{P}<0,05)$. The species richness presented conditions similar to those at the time of the installation of the experiment. The greater abundance of some species contributed to the reduction of diversity measured by the Shannon-Weaver Index, in relation to 1989. The increases provided by silvicultural systems varied according to the area, with tendency to reduce of rate the growth in both. The regeneration time ( 27 years) was not sufficient for the complete restoration of absolute dominance.
\end{abstract}

Keywords: forestry structure, forest restoration, natural regeneration, semiarid.

\section{INTRODUÇÃO}

A crescente demanda por produtos e serviços florestais e a abertura de áreas para agricultura e pecuária ultrapassou há muito o limite dos recursos das florestas tropicais úmidas, de modo que atualmente altas taxas de desmatamento incidem sobre florestas tropicais secas (FTS) em todo o mundo. As FTS estão entre os principais ecossistemas tropicais ameaçados e a intensa exploração requer esforços de restauração florestal que exigem uma melhor compreensão dos processos sucessionais e do reestabelecimento de parâmetros estruturais (QUESADA et al., 2009).

Relativamente ao atendimento à demanda dos produtos e serviços fornecidos pelas florestas, a principal alternativa para a obtenção racional, aliada à necessária conservação da biodiversidade e da capacidade de recomposição da estrutura das florestas, tem sido o uso manejo florestal sustentável. Esta ferramenta de intervenção florestal suscita a implementação de mecanismos que respeitem o poder de resiliência, considerando a necessidade de obtenção de colheitas futuras e a sustentabilidade e estabilidade do ecossistema.

Para esta tarefa, foram idealizados os sistemas silviculturais, os quais são entendidos como ferramentas voltadas para a operacionalização do manejo florestal sustentável, englobando processos de colheita, tratamentos silviculturais aplicados ao estoque remanescente, minimização de danos ao sítio e manutenção da produtividade, com a finalidade de garantir produções sustentáveis de bens e serviços fornecidos pelas florestas (SOUZA; SOARES, 2013).

Inseridos no contexto das florestas tropicais secas, os recursos florestais provenientes do componente arbóreoarbustivo das formações vegetais da Caatinga desempenham um relevante papel para a região semiárida brasileira. A lenha 
e o carvão de espécies nativas são essenciais ao suprimento do consumo industrial e a setores de transformação. Segundo o Instituo Brasileiro de Geografia e Estatística - IBGE (2017), em 2016, no Nordeste brasileiro, a produção declarada da extração de lenha foi 15,37 milhões de metros esteres e 354.810 toneladas de carvão vegetal. Ademais, a Caatinga fornece produtos florestais não madeireiros como sementes, forragem, plantas medicinais, óleos e taninos.

A colheita da lenha é realizada quase sempre de modo exploratório, sem utilização de práticas sustentáveis para o manejo da floresta, com aplicação não assistida de intervenções que variam quanto ao impacto sobre o ecossistema (MATTOS et al., 2015), podendo variar do corte seletivo ao corte raso da vegetação com a queima dos resíduos da exploração florestal (ARAÚJO; SILVA, 2010).

Porém, ainda não há conhecimento consolidado de informações a respeito de como essas intervenções podem influenciar a recuperação das formações vegetais da Caatinga, no tocante aos atributos de diversidade e estrutura, além da possibilidade do comprometimento do aproveitamento econômico racional dos recursos florestais da Caatinga, especialmente porque Lucena et al. (2016) afirmam que poucos estudos foram desenvolvidos nessa região visando entender a regeneração natural diante das diferentes formas de intervenção.

Portanto, esse conhecimento permitirá atestar como os sistemas silviculturais proporcionam à vegetação condições de renovação da capacidade produtiva e da regeneração dos ecossistemas florestais da Caatinga. Nesse sentido, para Velazco et al. 2015, conhecer a composição florística, a diversidade e a estrutura fitossocilógica da vegetação contribui grandemente para o correto manejo dos ecossistemas, sua recuperação, conservação e uso racional, especialmente diante das mudanças que podem advir do manejo.

Em face do exposto, o presente artigo visou investigar a composição florística, a diversidade e parâmetros estruturais proporcionados por quatro sistemas silviculturais ao componente arbóreo-arbustivo de uma formação florestal na Caatinga, em dois locais contíguos no Seridó do Rio Grande do Norte, com a finalidade de contribuir para o entendimento da regeneração da vegetação do bioma Caatinga mediante diferentes intervenções e modos de ocupação do solo.

\section{MATERIAL E MÉTODOS}

\section{1 Área de estudo}

A pesquisa foi feita, simultaneamente, em dois experimentos situados em áreas vizinhas, ambas localizadas na parte sudoeste do Rio Grande do Norte, no município de Serra Negra do Norte. O primeiro, contando com 4 ha de área experimental, está situado na Estação Ecológica do Seridó, doravante denominada EES, a qual está localizada nas coordenadas $06^{\circ} 35^{\prime}$ e $06^{\circ} 40^{\prime} \mathrm{S}$, e $37^{\circ} 20^{\prime}$ e $37^{\circ} 39^{\prime} \mathrm{W}$ (Datum SAD 69), cuja administração é atualmente responsabilidade do Instituto Chico Mendes da Conservação da Biodiversidade (ICMBIO). O outro, com 2,56 ha de área experimental, está localizado em uma propriedade particular, a Fazenda Pedro Cândido - denominada FPC, vizinha à EES. As áreas experimentais são separadas apenas por uma estrada vicinal de cerca de 10 metros de largura.

Segundo a Empresa Brasileira de Pesquisa Agropecuária EMBRAPA (2013), a área dos experimentos é caracterizada pela ocorrência de Luvissolos Crômicos, formados por material mineral pouco profundo, com presença de horizonte $\mathrm{B}$ textural ou $\mathrm{B}$ nítico, alto conteúdo de nutrientes e saturação por base por volta de $80 \%$. Para a caracterização química do solo, foram coletadas amostras de solo nas áreas experimentais, em todas as parcelas das duas áreas, conforme EMBRAPA (1997). A análise foi realizada pelo Laboratório de Solos e Água do CSTR, Universidade Federal de Campina Grande. Os atributos químicos foram submetidos à análise de variância (DBC) e teste de médias, utilizando-se o teste de Tukey a 5\% de significância.

O clima da região onde estão instalados os experimentos, conforme a classificação de Köppen (1996), é semiárido do tipo BsW'h'. Segundo informações da estação de observação meteorológica da EES, a temperatura média anual é de $30,7^{\circ} \mathrm{C}$ com média máxima ocorrendo em outubro $\left(31,0^{\circ} \mathrm{C}\right)$ e a mínima em fevereiro $\left(29,3^{\circ} \mathrm{C}\right)$, com média de umidade relativa do ar em torno de $50 \%$. A pluviosidade apresenta alta variação interanual (350 a $800 \mathrm{~mm}$ anuais), com média histórica em torno $600 \mathrm{~mm}$, concentrando-se de janeiro a maio (SANTANA; SOUTO, 2006). Observa-se também a ocorrência de aproximadamente 2.800 horas anuais de insolação.

A vegetação do Seridó é classificada como um tipo hiperxerófilo da Caatinga, de conformação arbóreo-arbustiva esparsa, caracterizada por árvores e arbustos de pequeno porte (de 3,5 a 4,5 $\mathrm{m}$ de altura média e média de DAP de 4,0 $\mathrm{cm}$ ). Outra característica é a ocorrência de cactáceas e estrato herbáceo sazonal, este quase totalmente restrito à estação chuvosa. Em alguns locais com melhores condições edáficas e em melhor estado de conservação ocorrem espécies arbóreas de maiores diâmetros e alturas. Alguns estudos cogitaram a hipótese de que a vegetação do Seridó seria uma tipologia com baixa diversidade florística e de menor produção de biomassa quando se compara com outras áreas da Caatinga (AMORIM et al., 2005; COSTA et al., 2009).

\subsection{Informações sobre o experimento}

As coletas de dados foram realizadas em experimentos já instalados em 1989 nos dois locais, os quais tinham a finalidade de comparar qualitativa e quantitativamente o comportamento, o ritmo e os padrões da regeneração do componente arbóreo-arbustivo da vegetação nativa. Segundo Araújo; Silva (2010), o experimento foi instalado na forma de um delineamento estatístico em blocos casualizados, com dois blocos, e consistiu na aplicação de quatro sistemas silviculturais com quatro repetições em cada bloco. Considerou-se cada um dos blocos a realização de pastejo não controlado de gado bovino, ovino e caprino na FPC e sua não realização na EES. Nesta localidade, o pastejo havia sido suspenso desde 1982.

Os sistemas silviculturais foram: CR - corte raso de todos os indivíduos das espécies arbóreo-arbustivas, sem restrição de diâmetro; $\mathrm{CS}_{+8}$ - corte seletivo de todos os indivíduos das espécies arbóreo-arbustivas com DNB $>8 \mathrm{~cm}$; CRQ - corte raso de todos os indivíduos das espécies arbóreo-arbustivas, sem restrição de diâmetro, com posterior queima dos resíduos da colheita (galhos, ramos e folhas) no local da colheita; CRDQ - corte raso de todos os indivíduos das espécies arbóreo-arbustivas, sem restrição de diâmetro, com posterior queima dos resíduos da colheita (galhos, ramos e folhas) no local da colheita e destoca do caule, permanecendo o sistema radicular no solo (ARAÚJO; SILVA, 2010). 


\subsection{Coleta de dados}

A circunferência dos fustes à altura de $1,30 \mathrm{~m}$ a partir do solo (CAP) foi mensurada em parcelas permanentes de $400 \mathrm{~m}^{2}$ em março de 2016. Foram incluídos os indivíduos com hábito arbóreo e arbustivo com CAP maior que seis centímetros (CAP $>6,0 \mathrm{~cm}$ ), segundo a metodologia de sugerida pelo Protocolo de Medições de Parcelas Permanentes (RMFC, 2005). A CAP foi medida com auxílio de fita métrica com precisão de $0,5 \mathrm{~cm}$.

Foi realizada a anotação dos indivíduos mensurados, com reconhecimento visual dos táxons em campo, conforme métodos de identificação preconizados pela Rede de Manejo Florestal da Caatinga - RMFC (2005). Também foi realizada a anotação, em campo, do nome vulgar, além do número de registro dos indivíduos em cada parcela, possibilitando sua localização posterior, bem como a avaliação dendrológica de suas características, visando ao seu reconhecimento conforme prévias informações referentes às espécies, registradas pela RMFC, nos dois locais de estudo. Posteriormente, com base no reconhecimento prévio de cada táxon, a grafia dos nomes científicos e dos classificadores das espécies foi atualizada conforme a Lista de Espécies da Flora do Brasil (FLORA DO BRASIL, 2017).

\subsection{Parâmetros avaliados}

No tocante à composição florística foi realizada a listagem de espécies. Posteriormente, foi calculada a diversidade florística, utilizando o Índice de Equabilidade de Pielou (J') (BROWER; ZAR, 1984) e a diversidade de Shannon-Weaver; (SOUZA; SOARES, 2013), conforme as seguintes expressões:

$$
\begin{aligned}
& \mathrm{J}^{\prime}=\left(\frac{\mathrm{H}^{\prime}}{\operatorname{Hmax}}\right) \\
& \mathrm{H}^{\prime}=\frac{\left[\mathrm{N} \cdot \operatorname{Ln}(\mathrm{N})-\sum_{\mathrm{i}=1}^{\mathrm{S}} \mathrm{n}_{\mathrm{i}} \operatorname{Ln}\left(\mathrm{n}_{\mathrm{i}}\right)\right]}{\mathrm{N}}
\end{aligned}
$$

em que: $H^{\prime}$ = Índice de diversidade de Shannon-Weaver; $\mathrm{n}_{\mathrm{i}}=$ número de indivíduos da i-ésima espécie; $\mathrm{N}=$ Número total de indivíduos; $\mathrm{S}=$ número total de espécies amostradas; $\mathrm{Ln}=$ logaritmo de base neperiana; J' = Equabilidade de Pielou; Hmáx $=$ Ln $(\mathrm{S})$.

Foi estimada a estrutura horizontal em cada sistema silvicultural, através da densidade absoluta, densidade relativa, valor de importância relativo (\%), dominância absoluta e relativa, conforme Mueller-Dombois e Ellenberg (1974), onde se considerou cada fuste como um indivíduo, de acordo com as seguintes expressões:

$$
\begin{aligned}
& \text { DAi }=\left(\frac{\text { nij }}{\mathrm{A}}\right) \\
& D R i=\left(\frac{\mathrm{DAi}}{\mathrm{DT}}\right) \times 100 \\
& \text { DoAi }=\left(\frac{\mathrm{Abi}}{\mathrm{A}}\right) \\
& \text { DoT }=\left(\frac{\mathrm{ABT}}{\mathrm{A}}\right) \\
& \text { DoR }=\left(\frac{\text { DoA }}{\text { DoT }}\right) \times 100 \\
& \mathrm{VIi}=\text { DRi }+ \text { DoRi }+ \text { FRi }
\end{aligned}
$$

em que: $\mathrm{Da}_{\mathrm{i}}=$ densidade absoluta da i-ésima espécie (fustes.ha$\left.{ }^{1}\right) \mathrm{N}_{\mathrm{ij}}=$ número de fustes da i-ésima espécies; $\mathrm{N}=$ número de total de fustes; $\mathrm{A}=$ área total amostrada (ha); $\mathrm{DR}_{\mathrm{i}}=$ densidade relativa da i-ésima espécie; $F_{\mathrm{i}}=$ frequência relativa da $\mathrm{i}$ ésima espécie; VIi = valor de importância da i-ésima espécie. DoA $_{i}=$ dominância absoluta da i-ésima espécie $\left(\mathrm{m}^{2} \cdot \mathrm{ha}^{-1}\right) ; \mathrm{AB}_{\mathrm{i}}$ = área basal da i-ésima espécie, em $\mathrm{m}^{2}$ por área amostrada; $\mathrm{A}$
$=$ Área amostrada (ha); $\mathrm{ABT}=\sum_{\mathrm{i}=1}^{\mathrm{S}} \mathrm{ABi} ; \mathrm{DoR}_{\mathrm{i}}=$ dominância relativa da i-ésima espécie; DoT $=$ soma da dominância de todas as espécies $\mathrm{em} \mathrm{m}^{2} \cdot \mathrm{ha}^{-1}$.

A frequência relativa de cada espécie não foi discutida e nem apresentada nas tabelas, sendo utilizada para a composição do valor de importância relativo (\%), uma vez que a escassez de informações a seu respeito em áreas de Caatinga sob intervenções silviculturais impossibilita a discussão. $\mathrm{O}$ incremento periódico em dominância absoluta (IP) do período de 1989 a 2016 para cada um dos sistemas silviculturais foi obtido subtraindo-se o valor atual da dominância absoluta de cada sistema silvicultural do valor dos dados apresentados por Araújo; Silva (2010), referente a 1989 para os mesmos sistemas silviculturais. O incremento médio anual (IMA) foi calculado pela divisão do incremento periódico de 1989 a 2016 por 27, que é o lapso temporal compreendido neste período. Da mesma forma, para o IMA registrado em 2004, mas dividindo a dominância absoluta registrada em 2004 (ARAÚJO; SILVA, 2010) por 15, que é o período de tempo compreendido.

Aos valores médios de diversidade, medida pelo índice de diversidade Equabilidade de Pielou (J') foi empregada análise de variância, sendo realizada a comparação múltipla das médias a $5 \%$ de probabilidade de erro pelo teste de Tukey $(\mathrm{P}<0,05)$.

\section{RESULTADOS}

A Tabela 1 apresenta os valores médios dos atributos químicos do solo, coletados nas parcelas dos sistemas silviculturais, tanto na Estação Ecológica do Seridó quanto na Fazenda Pedro Cândido. A riqueza de espécies, referente aos sistemas silviculturais, variou conforme o local avaliado. $\mathrm{Na}$ $\mathrm{EES}$, as maiores riquezas foram registradas nos $\mathrm{CS}_{+8}$ e CRDQ, cuja superioridade ocorreu pela presença de espécies com poucos indivíduos, tais como Amburana cearensis (Allemão) A.C.Sm, Senna macranthera (Collad.) Irwin \& Barneby e Tabebuia couralia Splitg. (Tabela 2).

$\mathrm{Na}$ FPC, as maiores riquezas foram registradas nos sistemas silviculturais CRQ, $\mathrm{CS}_{+8}$ e CR. As espécies Mimosa tenuiflora e Croton blanchetianus, aparentam demonstrar, quanto ao número de ramificações do fuste, relação proporcional com a severidade dos sistemas silviculturais, cujos maiores números foram constatados nos CRQD, CR e CRQ (Tabela 3).

Constata-se que, com relação aos levantamentos realizados por Araújo; Silva (2010) em 2004, com exceção do sistema silvicultural CRQ na FPC, todos tiveram redução da riqueza. Vê-se que, em comparação a antes das intervenções (1989), apesar de atualmente haver uma menor área de amostragem, a riqueza permaneceu estável (Tabela 4).

A menor riqueza de espécies, comparando-se a inventários realizados em 1989 e 2004, culminou na diminuição da diversidade geral medida pelo Índice de Shannon-Weaver, relativamente aos valores registrados por Araújo; Silva (2010), conforme Tabela 5. Constata-se que, na comparação entre os locais avaliados, a diversidade não diferiu estatisticamente, nem entre os sistemas silviculturais nem entre as áreas. Contudo, a diversidade propiciada pelo CRDQ em ambas as áreas foi inferior aos valores registrados nos demais sistemas silviculturais (Tabela 6). 
Tabela 1. Médias dos atributos químicos do solo (pH, Soma de bases -SB, CTC - T\% e Saturação por bases - V\%) e médias dos elementos $\mathrm{P}$ e $\mathrm{Ca} \mathrm{Mg}, \mathrm{K}, \mathrm{Na}$ e $\mathrm{H}+\mathrm{Al}$, referentes às parcelas das intervenções e ao blocos, Serra Negra do Norte-RN, Brasil.

Table 1. Averages of soil chemical attributes ( $\mathrm{pH}$, Sum of bases $-\mathrm{SB}$, cation exchange capacity $-\mathrm{T} \%$ e base saturation - V\%) and averages of elements $\mathrm{P}, \mathrm{Ca} \mathrm{Mg}, \mathrm{K}, \mathrm{Na}$ e H+Al, concerning the plots of the interventions, Serra Negra do Norte-RN, Brazil.

\begin{tabular}{|c|c|c|c|c|c|c|c|c|c|c|}
\hline \multirow{3}{*}{$\begin{array}{c}\text { Sistema } \\
\text { Silvicultural }\end{array}$} & \multicolumn{10}{|c|}{ Parâmetros Avaliados } \\
\hline & $\mathrm{pH}$ & $\mathrm{P}$ & $\mathrm{Ca}$ & $\mathrm{Mg}$ & $\mathrm{K}$ & $\mathrm{Na}$ & $\mathrm{H}+\mathrm{Al}$ & SB & T\% & V\% \\
\hline & & \multicolumn{2}{|c|}{$\left(\mathrm{mg} \cdot \mathrm{dm}^{-3}\right)$} & \multicolumn{5}{|c|}{$\left(\mathrm{cmol}_{\mathrm{c}} \mathrm{dm}^{-3}\right)$} & & \\
\hline CR & $5,25 a$ & $2,99 a$ & $5,17 \mathrm{a}$ & $2,87 \mathrm{a}$ & $0,18 \mathrm{a}$ & $0,22 \mathrm{a}$ & $1,57 \mathrm{a}$ & $8,44 a$ & $10,02 \mathrm{a}$ & $82,3 a$ \\
\hline $\mathrm{CS}_{+8}$ & $5,32 a$ & $2,40 \mathrm{a}$ & $5,42 \mathrm{a}$ & $3,29 \mathrm{a}$ & $0,17 \mathrm{a}$ & $0,23 \mathrm{a}$ & $1,60 \mathrm{a}$ & $9,13 \mathrm{a}$ & $10,72 \mathrm{a}$ & $84,3 a$ \\
\hline CRQ & $5,42 \mathrm{a}$ & $2,55 \mathrm{a}$ & $5,95 \mathrm{a}$ & $3,40 \mathrm{a}$ & $0,19 \mathrm{a}$ & $0,24 \mathrm{a}$ & $1,50 \mathrm{a}$ & $9,78 \mathrm{a}$ & $11,28 \mathrm{a}$ & $86,5 a$ \\
\hline CRDQ & $5,42 \mathrm{a}$ & $3,10 \mathrm{a}$ & $6,04 \mathrm{a}$ & $3,21 \mathrm{a}$ & $0,15 \mathrm{a}$ & $0,32 \mathrm{a}$ & $1,91 \mathrm{a}$ & $9,72 \mathrm{a}$ & $11,64 a$ & $84,3 \mathrm{a}$ \\
\hline \multicolumn{11}{|c|}{ Blocos } \\
\hline EES & $5,53 a$ & $3,04 a$ & $5,40 \mathrm{a}$ & $2,98 \mathrm{a}$ & $0,19 \mathrm{a}$ & $0,22 b$ & $1,63 \mathrm{a}$ & $8,79 a$ & $10,43 a$ & $83,7 \mathrm{a}$ \\
\hline FPC & $5,18 b$ & $2,48 \mathrm{a}$ & $5,89 \mathrm{a}$ & $3,40 \mathrm{a}$ & $0,16 \mathrm{a}$ & $0,29 \mathrm{a}$ & $1,66 \mathrm{a}$ & $9,75 \mathrm{a}$ & $11,41 \mathrm{a}$ & $84,4 a$ \\
\hline
\end{tabular}

CR - corte raso; CRQ - corte raso com queima; CRDQ - corte raso com destoca e queima; CS - corte seletivo (ARAÚJO; SILVA, 2010). EES: Estação Ecológica do Seridó; FPC: Fazenda Pedro Cândido. *Médias nas colunas seguidas de mesma letra não diferem entre si pelo teste de Tukey a 5\% (P<0,05).

Tabela 2. Lista de famílias, de espécies e número de fustes registrados nos sistemas silviculturais (CR - corte raso; CRQ - corte raso com queima; CRDQ - corte raso com destoca e queima; CS - corte seletivo) na Estação Ecológica do Seridó, Serra Negra do Norte-RN, Brasil.

Table 2. List of families, of species and number of stems registered in silvicultural systems (CR - general cut; CRQ -general cut of all individuals and subsequent burning of crop residues; CRDQ - general cut with subsequent burning of crop residues and removal of stem from soil; CS - selective cut) in the Seridó Ecological Station Serra Negra do Norte-RN, Brazil.

\begin{tabular}{|c|c|c|c|c|c|c|}
\hline Família & Nome científico & Nome comum & $\mathrm{CR}$ & CRQ & CRDQ & $\mathrm{CS}$ \\
\hline \multirow[t]{8}{*}{ Fabaceae } & Poincianella pyramidalis (Tul.) L. P. Queiroz & Catingueira & 522 & 475 & 674 & 402 \\
\hline & Mimosa tenuiflora (Willd.) Poir & Jurema preta & 47 & 95 & 48 & 70 \\
\hline & Anadenanthera colubrina (Vell.) Brenan & Angico & 38 & 51 & 14 & 35 \\
\hline & Mimosa ophthalmocentra Mart. ex Benth. & Jurema branca & 18 & 16 & 20 & 24 \\
\hline & Bauhinia forficata Link & Mororó & 1 & - & 10 & 5 \\
\hline & Amburana cearensis & Cumaru & - & - & 1 & - \\
\hline & Senna macranthera (Collad.) Irwin \& Barneby & São João & - & - & - & 4 \\
\hline & Libidibia ferrea (Mart. ex Tul.) L.P.Queiroz & Jucá & 2 & 9 & - & - \\
\hline \multirow{3}{*}{ Euphorbiaceae } & Croton blanchetianus Baill. & Marmeleiro & 54 & 70 & 128 & 124 \\
\hline & Cnidoscolus quercifolius Pohl & Faveleira & 24 & 9 & 28 & 12 \\
\hline & Manihot caerulescens Pohl & Maniçoba & - & - & 2 & 3 \\
\hline \multirow[t]{2}{*}{ Combretaceae } & Combretum leprosum Mart. & Mofumbo & 7 & 36 & 31 & 4 \\
\hline & Combretum laxum Jacq. & Bugi & - & - & 1 & 4 \\
\hline Burseraceae & Commiphora leptophloeos (Mart.) J.B.Gillet & Imburana & 57 & 36 & 54 & 134 \\
\hline Apocynaceae & Aspidosperma pyrifolium Mart. & Pereiro & 63 & 40 & 9 & 122 \\
\hline Erythroxylaceae & Erythroxylum pungens O.E.Schulz & Rompe Gibão & 29 & 24 & 7 & 24 \\
\hline Bignoniaceae & Tabebuia couralia Splitg. & Pau d'arco roxo & - & 4 & 10 & - \\
\hline Capparaceae & Cynophalla flexuosa (L.) J.Presl & Feijão-Bravo & - & 2 & - & \\
\hline Anacardiaceae & Myracrodruon urundeuva Allemão & Aroeira & - & - & - & - \\
\hline Não identificada & & & - & 7 & - & 6 \\
\hline TOTAL & & & 862 & 874 & 1037 & 973 \\
\hline
\end{tabular}

Tabela 3. Lista de famílias, de espécies e número de fustes registrados nos sistemas silviculturais (CR - corte raso; CRQ - corte raso com queima; CRDQ - corte raso com destoca e queima; CS - corte seletivo) na Fazenda Pedro Cândido, Serra Negra do Norte-RN, Brasil.

Table 3. List of families, of species and number of stems registered in silvicultural systems (CR - general cut; CRQ - general cut of all individuals and subsequent burning of crop residues; CRDQ - general cut with subsequent burning of crop residues and removal of stem from soil; CS - selective cut) in the Pedro Cândido Farm, Serra Negra do Norte-RN, Brazil.

\begin{tabular}{cllcccc}
\hline \multicolumn{1}{c}{ Nome científico } & Nome comum & CR & CRQ & CRDQ & CS \\
\hline Famália & \multicolumn{1}{c}{ Catingueira } & 93 & 40 & 26 & 118 \\
& Poincianella pyramidalis (Tul.) L. P. Queiroz & Jurema preta & 78 & 128 & 433 & 40 \\
& Anadenanthera colubrina (Vell.) Brenan & Angico & 4 & 2 & - & 14 \\
& Mimosa ophthalmocentra Mart. ex Benth. & Jurema branca & 32 & 6 & 11 & - \\
& Senna macranthera (Collad.) Irwin \& Barneby & São João & - & 2 & - & 9 \\
& Libidibia ferrea (Mart. ex Tul.) L.P.Queiroz & Jucá & 3 & 2 & - & - \\
Euphorbiaceae & Croton blanchetianus Baill. & Marmeleiro & 181 & 179 & 141 & 109 \\
& Cnidoscolus quercifolius Pohl & Faveleira & 16 & 7 & 26 & 29 \\
Combretaceae & Manihot caerulescens Pohl & Maniçoba & - & - & - & - \\
& Combretum leprosum Mart. & Mofumbo & 114 & 44 & 8 & 31 \\
Burseraceae & Combretum laxum Jacq. & Bugi & - & - & - & - \\
Apocynaceae & Aspidosperma pyrifolium Mart. & Imburana & 23 & - & - & 4 \\
Erythroxylaceae & Erythroxylum pungens O.E.Schulz & Pereiro & 155 & 221 & 72 & 244 \\
Anacardiaceae & Myracrodruon urundeuva Allemão & Rompe Gibão & 2 & 2 & - & 43 \\
Não identificada & & Aroeira & 1 & - & - & - \\
\hline TOTAL & & & - & 3 & - & 2 \\
\hline
\end{tabular}


Tabela 4. Riqueza de espécies, por sistema silvicultural (CR - corte raso; CRQ - corte raso com queima; CRDQ - corte raso com destoca e queima; CS - corte seletivo), em medições realizadas antes das intervenções (1989), 15 anos depois (2004) e em 2016, em Serra Negra do Norte-RN, Brasil.

Table 4. Species richness, by silvicultural system (CR - general cut; CRQ - general cut of all individuals and subsequent burning of crop residues; CRDQ - general cut with subsequent burning of crop residues and removal of stem from soil; CS - selective cut), measurements carried out before the interventions (1989), 15 years later (2004) and in 2016, in Serra Negra do Norte-RN, Brazil.

\begin{tabular}{ccccccc}
\hline \multirow{2}{*}{ S.S. } & \multicolumn{2}{c}{$1989^{*}$} & \multicolumn{2}{c}{$2004^{*}$} & \multicolumn{2}{c}{2016} \\
\cline { 2 - 7 } CR & FPC & EES & FPC & EES & FPC \\
\hline CRQ & 11 & 12 & 16 & 13 & 12 & 11 \\
CRDQ & 12 & 10 & 16 & 9 & 14 & 12 \\
CS+8 & 13 & 13 & 18 & 16 & 15 & 7 \\
Área Amostrada (ha) & 2,56 & 2,56 & 0,64 & 0,64 & 0,64 & 0,64 \\
\hline S.S = Sistema Silvicultural; EES = Estaça Ecológica do Seridó; FPC $=$ \\
Fazenda Pedro Cândido; *Obtidos de Araújo; Silva (2010).
\end{tabular}

Tabela 5. Médias do Índice de diversidade de Shannon-Weaver (nats.ind-1) antes (1989) e após as intervenções Silviculturais (CR corte raso; CRQ - corte raso com queima; CRDQ - corte raso com destoca e queima; CS - corte seletivo), em 2004 e 2016, na Estação Ecológica do Seridó e Fazenda Pedro Cândido, Serra Negra do Norte$\mathrm{RN}$, Brasil.

Table 5. Averages of the Diversity Index of Shannon-Weaver (nats.ind-1) before (1989) and after the Silvicultural interventions (CR - general cut; CRQ - general cut of all individuals and subsequent burning of crop residues; CRDQ - general cut with subsequent burning of crop residues and removal of stem from soil; CS - selective cut), in 2004 and 2106, in the Seridó Ecological (EES) Station and Pedro Cândido Farm (FPC), Serra Negra do Norte-RN, Brazil.

\begin{tabular}{ccccc}
\hline \multirow{2}{*}{ S.S } & \multicolumn{4}{c}{$1989^{*}$} \\
\cline { 2 - 5 } & CR & CRDQ & CRQ & CS $_{+8}$ \\
\hline EES & 2,07 & 1,81 & 2,01 & 2,07 \\
FPC & 1,69 & 1,62 & 1,65 & 1,77 \\
& \multicolumn{4}{c}{2004} \\
S.S & CR & CRDQ & CRQ & CS +8 \\
EES & 1,77 & 1,51 & 1,92 & 2,01 \\
FPC & 1,77 & 1,51 & 1,39 & 1,81 \\
& \multicolumn{4}{c}{2016} \\
S.S & CR & CRDQ & CRQ & CS+8 \\
EES & 1,50 & 1,36 & 1,69 & 1,85 \\
FPC & 1,91 & 1,21 & 1,60 & 1,81 \\
\hline
\end{tabular}

S.S = Sistema Silvicultural; *Obtidos de Araújo; Silva (2010).

No tocante às dominâncias absolutas proporcionadas pelos sistemas silviculturais, na Estação Ecológica do Seridó o $\mathrm{CS}_{+8}$ superou os demais, seguido pelo CRDQ. A superioridade do $\mathrm{CS}_{+8}$ e CRDQ deveu-se às maiores dominâncias absolutas apresentadas pelas espécies $P$. pyramidalis e C. leptophloeos (Tabela 7).

Não foi possível observar um padrão claro de respostas das variáveis estruturais aos sistemas silviculturais. Poder-se-ia esperar que elas fossem quantitativamente menores naqueles sistemas silviculturais onde o potencial de dano fosse maior, uma vez que operações como a queima dos resíduos da colheita sobre o solo desnudo podem degradar o banco de sementes, além de ter implicações negativas sobre as condições do solo (redução da matéria orgânico do solo, interrupção da ciclagem natural de nutrientes). No caso da destoca, há o risco de se produzir severos impactos sobre a regeneração, haja vista que a rebrota é um importante de mecanismo de resiliência das formações florestais da Caatinga.

Ao contrário, o CRDQ, o qual poderia ser considerado aquele com maior potencial de dano, apresentou as segundas maiores densidades e dominâncias absolutas. Contudo, destaca-se que, no CRDQ, os valores superiores ao CRQ e CR ocorreram em função das maiores densidades e dominâncias de $P$. pyramidalis.

Tabela 6. Valores médios da diversidade medida pelo Índice de equabilidade de Pielou (J'), considerando o efeito de cada sistema silvicultural (CR - corte raso; CRQ - corte raso com queima; CRDQ - corte raso com destoca e queima; CS - corte seletivo) na Estação Ecológica do Seridó (EES) e Fazenda Pedro Cândido (FPC), Serra Negra do Norte-RN, Brazil.

Table 6. Mean values of diversity measured by the Pielou Equability Index (J'), considering the effect of each silvicultural system (CR general cut; CRQ - general cut of all individuals and subsequent burning of crop residues; CRDQ - general cut with subsequent burning of crop residues and removal of stem from soil; CS selective cut), in the Serido Ecological Station (EES) and Pedro Cândido Farm (FPC), Serra Negra do Norte-RN, Brazil.

\begin{tabular}{ccc}
\hline \multirow{2}{*}{ Sistema Silvicultural } & \multicolumn{2}{c}{ J' } \\
\cline { 2 - 3 } & EES & FPC \\
\hline CR $^{*}$ & 0,6375 a A & 0,7825 a A \\
CS* $^{*}$ CRQ $^{*}$ & 0,7475 a A & 0,8025 a A \\
CRDQ $^{*}$ & 0,6925 a A & 0,7575 a A \\
\hline
\end{tabular}

Para médias nas colunas, seguidas da mesma letra, os tratamentos não diferem entre si e, nas linhas, médias seguidas de mesma letra, as áreas não diferem pelo Teste de Tukey a $5 \%(\mathrm{P}<0,05)$.

Na FPC, tratando-se do valor de importância, M. tenuiflora foi a mais importante nas parcelas do CRQ e CRDQ. Já no CR, quem mais se destacou foi $C$. blanchetianus, enquanto no $\mathrm{CS}_{+8}$ se sobressaiu $A$. pyrifolium. Em relação a $P$. pyramidalis, ela foi a segunda mais importante nas parcelas do $\mathrm{CS}_{+8}$ e $\mathrm{CR}$, mas com grande decréscimo dos valores de densidade absoluta e dominância absoluta em relação à Estação Ecológica do Seridó (Tabela 8).

Tratando-se da dinâmica da dominância absoluta, pode-se constatar que o desenvolvimento variou conforme os locais pesquisados, onde os sistemas silviculturais localizados na EES apresentaram maior ritmo de crescimento, com destaque para o $\mathrm{CS}_{+8}$ (Tabela 9). Tanto o incremento periódico (IP) para o período 1989-2016 quanto o incremento médio anual (IMA) para este período tiveram melhor desempenho na EES. Nos dois locais e em todos os sistemas silviculturais se observa, com exceção do $\mathrm{CS}_{+8}$ localizado na EES, redução do IMA (1989-2016) no que diz respeito ao IMA registrado para o período 1989-2004, evidenciando redução do ritmo de crescimento.

\section{DISCUSSÃO}

$\mathrm{Na}$ Estação Ecológica do Seridó, as espécies $P$. pyramidalis, $C$. blanchetianus, $M$. tenuiflora e $C$. leprosum tiveram, em relação ao número de ramificações do fuste, comportamento proporcional à severidade dos sistemas silviculturais, sendo registradas em sua maioria nas parcelas do CRDQ e CRQ. Por outro lado, houve espécies que não apresentaram número de ramificações do fuste proporcionais à intensidade das intervenções, a exemplo de A. pyrifolium, $M$. ophthalmocentra e C. leptophloeos. 
Tabela 7. Densidade - DA (fustes ha ${ }^{-1}$ ) e densidade relativa (DR), dominância absoluta e relativa (DoA e DoR) e valor de importância relativo das principais espécies em cada sistema silvicultural (CR - corte raso; CRQ - corte raso com queima; CRDQ - corte raso com destoca e queima; CS - corte seletivo) na Estação Ecológica do Seridó, Serra Negra do Norte-RN, Brasil.

Table 7. Absolute density - DA (stems ha ${ }^{-1}$ ) and relative density (DR), absolute and relative dominance (DoA e DoR) and relative importance value of the main species in each silvicultural system (CR - general cut; CRQ - general cut of all individuals and subsequent burning of crop residues; CRDQ - general cut with subsequent burning of crop residues and removal of stem from soil; CS - selective cut), in the Seridó Ecological Station, Serra Negra do Norte-RN, Brazil.

\begin{tabular}{|c|c|c|c|c|c|c|c|c|c|c|}
\hline \multirow{2}{*}{ Espécie } & \multicolumn{5}{|c|}{$\mathrm{CR}$} & \multicolumn{5}{|c|}{ CRQ } \\
\hline & $\mathrm{DA}$ & $\mathrm{DR}$ & DoA & DoR & VI $(\%)$ & DA & DR & DoA & DoR & VI (\%) \\
\hline P. pyramidalis & 3262 & 60,56 & 3,406 & 51,05 & 41,12 & 2968 & 54,35 & 2,690 & 42,26 & 36,37 \\
\hline D.E. & $356^{1}$ & $6,61^{1}$ & $0,25^{1}$ & $3,82^{1}$ & $12,3^{1}$ & $443,{ }^{2}$ & $8,13^{2}$ & $0,699^{2}$ & $10,9^{2}$ & $15,76^{2}$ \\
\hline M. tenuiflora & 293 & 5,45 & 0,808 & 12,11 & 9,78 & 593 & 10,87 & 1,020 & 16,03 & 13,13 \\
\hline C. leptophloeos & 356 & 6,61 & 0,814 & 12,20 & 9,21 & 225 & 4,12 & 0,590 & 9,26 & 8,63 \\
\hline A. colubrina & 237 & 4,41 & 0,636 & 9,53 & 8,57 & 318 & 5,84 & 0,760 & 11,95 & 9,05 \\
\hline A. pyrifolium & 393 & 7,31 & 0,215 & 3,22 & 7,43 & 250 & 4,58 & 0,126 & 1,97 & 5,31 \\
\hline C. blanchetianus & 337 & 6,26 & 0,256 & 3,83 & 6,31 & 437 & 8,01 & 0,288 & 4,53 & 7,30 \\
\hline C. quercifolius & 150 & 2,78 & 0,283 & 4,24 & 5,28 & D.E. ${ }^{2}$ & D.E. $^{2}$ & D.E. ${ }^{2}$ & D.E. ${ }^{2}$ & D.E. $^{2}$ \\
\hline C. leprosum & D.E. ${ }^{1}$ & D.E. ${ }^{1}$ & D.E. ${ }^{1}$ & D.E. ${ }^{1}$ & D.E. ${ }^{2}$ & 225 & 4,12 & 0,190 & 2,99 & 4,45 \\
\hline Total & 5387 & 100 & 6,672 & 100 & 100 & 5462 & 100 & 6,364 & 100 & 100 \\
\hline \multirow{2}{*}{ Espécie } & \multicolumn{5}{|c|}{ CRDQ } & \multicolumn{5}{|c|}{$\mathrm{CS}$} \\
\hline & DA & DR & DoA & DoR & VI $(\%)$ & DA & DR & DoA & DoR & VI (\%) \\
\hline P.pyramidalis & 4212 & 65,0 & 3,672 & 51,30 & 42,37 & 2512 & 41,32 & 4,272 & 35,18 & 28,92 \\
\hline D.E. & $375^{3}$ & $5,79^{3}$ & $0,32^{3}$ & $4,42^{3}$ & $17,8^{3}$ & $537^{4}$ & $8,84^{4}$ & $0,626^{4}$ & $5,17^{4}$ & $18,3^{4}$ \\
\hline C. blanchetianus & 800 & 12,34 & 0,610 & 8,52 & 10,56 & 775 & 12,74 & 0,873 & 7,19 & 10,06 \\
\hline C. leptophloeos & 337 & 5,21 & 1,057 & 14,76 & 9,36 & 837 & 13,77 & 2,573 & 21,19 & 14,22 \\
\hline M. tenuiflora & 300 & 4,6 & 0,564 & 7,88 & 5,97 & 437 & 7,19 & 2,392 & 19,70 & 12,38 \\
\hline C. leprosum & 194 & 2,99 & 0,140 & 1,96 & 5,25 & D.E. ${ }^{4}$ & D.E. ${ }^{4}$ & D.E. ${ }^{4}$ & D.E. ${ }^{4}$ & D.E. ${ }^{4}$ \\
\hline C. quercifolius & 175 & 2,70 & 0,386 & 5,39 & 4,50 & D.E. $^{4}$ & D.E. ${ }^{4}$ & D.E. $^{4}$ & D.E. ${ }^{4}$ & D.E. $^{4}$ \\
\hline A. colubrina & 87 & 1,35 & 0,414 & 5,78 & 4,18 & 219 & 3,60 & 0,531 & 4,37 & 6,07 \\
\hline A. pyrifolium & D.E. ${ }^{3}$ & D.E. ${ }^{3}$ & D.E. ${ }^{3}$ & D.E. ${ }^{3}$ & D.E. ${ }^{3}$ & 762 & 12,54 & 0,876 & 7,22 & 10,00 \\
\hline Total & 6481 & 100 & 7,159 & 100 & 100 & 6081 & 100 & 12,14 & 100 & 100 \\
\hline
\end{tabular}

D.E. ${ }^{1}=$ Demais espécies CR: Erythroxylum pungens, Mimosa ophthalmocentra, Combretum leprosum, Caesalpinia ferrea, Bauhinia forficata; D.E. ${ }^{2}=$ Demais espécies CRQ: Erythroxylum pungens, Mimosa ophthalmocentra, Cnidoscolus quercifolius, Caesalpinia ferrea, Tabebuia couralia, Não identificada, Cynophalla flexuosa; D.E. ${ }^{3}=$ Demais espécies CRDQ: Mimosa ophthalmocentra, Tabebuia couralia, Aspidosperma pyrifolium, Erythroxylum pungens, Bauhinia forficata, Amburana cearensis, Manihot caerulescens, Combretum laxum; D.E. ${ }^{4}=$ Demais espécies CS: Mimosa ophthalmocentra, Erythroxylum pungens, Cnidoscolus quercifolius, Combretum leprosum, Bauhinia forficata, Senna macranthera, Combretum laxum, Manihot caerulescens, Não identificada

Tabela 8. Densidade absoluta - DA (fustes $\mathrm{ha}^{-1}$ ) e densidade relativa (DR), dominância absoluta e relativa (DoA e DoR) e valor de importância relativo das principais espécies em cada sistema silvicultural (CR - corte raso; CRQ - corte raso com queima; CRDQ - corte raso com destoca e queima; CS - corte seletivo) na Fazenda Pedro Cândido, Serra Negra do Norte-RN, Brasil.

Table 8. Absolute density - DA (stems ha ${ }^{-1}$ ) and relative density (DR), absolute and relative dominance (DoA e DoR) and relative importance value of the main species in each silvicultural system (CR - general cut; CRQ - general cut of all individuals and subsequent burning of crop residues; CRDQ - general cut with subsequent burning of crop residues and removal of stem from soil; CS - selective cut), in the Pedro Cândido Farm, Serra Negra do Norte-RN, Brazil.

\begin{tabular}{|c|c|c|c|c|c|c|c|c|c|c|}
\hline \multirow{2}{*}{ Espécie } & \multicolumn{5}{|c|}{$\mathrm{CR}$} & \multicolumn{5}{|c|}{ CRQ } \\
\hline & $\mathrm{DA}$ & DR & DoA & DoR & VI $(\%)$ & DA & DR & DoA & DoR & VI (\%) \\
\hline C. blanchetianus & 1131 & 25,78 & 0,842 & 15,51 & 17,37 & 1118 & 28,14 & 0,800 & 20,87 & 21,28 \\
\hline P. pyramidalis & 581 & 13,25 & 1,152 & 21,23 & 15,10 & 250,0 & 6,29 & 0,451 & 11,76 & 9,72 \\
\hline A. pyrifolium & 968 & 22,08 & 0,491 & 9,04 & 13,98 & 1381,2 & 34,75 & 0,702 & 18,32 & 22,63 \\
\hline M.tenuiflora & 487 & 11,11 & 1,166 & 21,48 & 13,57 & 800,0 & 20,13 & 1,424 & 37,15 & 24,03 \\
\hline C. leprosum & 712 & 16,24 & 0,579 & 10,67 & 12,57 & 275,0 & 6,92 & 0,173 & 4,50 & 7,51 \\
\hline C. leptophloeos & 143 & 3,28 & 0,510 & 9,40 & 7,83 & D.E. ${ }^{2}$ & D.E. ${ }^{2}$ & D.E. ${ }^{2}$ & D.E. ${ }^{2}$ & D.E. ${ }^{2}$ \\
\hline D.E. & $362^{1}$ & $8,26^{1}$ & $0,688^{1}$ & $12,6^{1}$ & $19,58^{1}$ & $150^{2}$ & $3,75^{2}$ & $0,284^{2}$ & $7,4^{2}$ & $14,83^{2}$ \\
\hline Total & 4387 & 100 & 5,429 & 100 & 100 & 3975 & 100 & 3,8 & 100 & 100 \\
\hline \multirow{2}{*}{ Espécie } & \multicolumn{5}{|c|}{ CRDQ } & \multicolumn{5}{|c|}{$\mathrm{CS}$} \\
\hline & DA & DR & DoA & DoR & VI (\%) & DA & DR & DoA & DoR & VI (\%) \\
\hline M. tenuiflora & 2706 & 60,39 & 4,625 & 75,7 & 51,73 & 250 & 6,22 & 0,752 & 10,73 & 10,25 \\
\hline C. blanchetianus & 881 & 19,67 & 0,483 & 7,91 & 15,54 & 681 & 16,95 & 0,448 & 6,39 & 12,38 \\
\hline D.E. & 281 & 6,28 & 0,445 & 7,29 & 14,04 & $362^{4}$ & $9,02^{4}$ & $0,633^{4}$ & $9,02^{4}$ & $12,92^{4}$ \\
\hline A. pyrifolium & 450 & 10,04 & 0,242 & 3,96 & 11,02 & 1525 & 37,95 & 1,812 & 25,84 & 25,86 \\
\hline C. quercifolius & 162 & 3,63 & 0,311 & 5,10 & 7,67 & 181 & 4,51 & 0,747 & 10,66 & 7,35 \\
\hline P. pyramidalis & D.E. ${ }^{3}$ & D.E. ${ }^{3}$ & D.E. ${ }^{3}$ & D.E. ${ }^{3}$ & D.E. ${ }^{3}$ & 737 & 18,35 & 2,334 & 33,30 & 21,81 \\
\hline E. pungens & D.E. ${ }^{3}$ & D.E. ${ }^{3}$ & D.E. ${ }^{3}$ & D.E. ${ }^{3}$ & D.E. ${ }^{3}$ & 268 & 6,69 & 0,275 & 3,93 & 8,14 \\
\hline Total & 4481 & 100 & 6,107 & 100 & 100 & 4018 & 100 & 7,011 & 100 & 100 \\
\hline
\end{tabular}

D.E. ${ }^{1}=$ Demais espécies CR: Mimosa ophthalmocentra, Cnidoscolus quercifolius, Anadenanthera colubrina, Erythroxylum pungens, Caesalpinia ferrea, Myracrodruon urundeuva; D.E. ${ }^{2}=$ Demais espécies CRQ: Cnidoscolus quercifolius, Mimosa ophthalmocentra, Não identificada, Anadenanthera colubrina, Caesalpinia ferrea, Erythroxylum pungens, Senna macranthera; D.E. ${ }^{3}=$ Demais espécies CRDQ: Poincianella pyramidalis, Combretum leprosum, Mimosa ophthalmocentra; D.E. ${ }^{4}=$ Demais espécies CS: Anadenanthera colubrina, Combretum leprosum, Senna macranthera, Commiphora leptophloeos, Não identificada. 
Tabela 9. Dominância absoluta - DoA $\left(\mathrm{m}^{2} \mathrm{ha}^{-1}\right)$ referente aos anos de 1989 e 2016, incremento periódico - IP ( $\mathrm{m}^{2}$ ha 1$)$ relativo ao período 1989-2016 e incremento médio anual - IMA $\left(\mathrm{m}^{2} \mathrm{ha}^{-1} \mathrm{ano}^{-1}\right)$ referente às intervenções (CR - corte raso; CRQ - corte raso com queima; CRDQ - corte raso com destoca e queima; CS - corte seletivo) em 2004 e 2016 na Estação Ecológica do Seridó (EES) e Fazenda Pedro Cândido (FPC), Serra Negra do Norte-RN, Brasil.

Table 9. Absolute dominance- DoA $\left(\mathrm{m}^{2} \mathrm{ha}^{-1}\right)$ referring to the years 1989 and 2016, periodic increase - IP $\left(\mathrm{m}^{2}\right.$ ha $\left.\mathrm{C}^{-1}\right)$ for the period 1989-2016 and average annual increment - IMA $\left(\mathrm{m}^{2} \mathrm{ha}^{-1} \mathrm{ano}^{-1}\right)$ for interventions (CR - general cut; CRQ - general cut of all individuals and subsequent burning of crop residues; CRDQ - general cut with subsequent burning of crop residues and removal of stem from soil; CS - selective cut) in 2004 and 2016 in the Seridó Ecological Station (EES) and Pedro Cândido Farm (FPC), Serra Negra do Norte-RN, Brazil.

\begin{tabular}{|c|c|c|c|c|c|c|c|c|c|c|c|c|}
\hline \multirow{2}{*}{ S.S } & \multicolumn{2}{|c|}{ DA $1989^{*}$} & \multicolumn{2}{|c|}{ DA (logo após 1989) } & \multicolumn{2}{|c|}{ DA 2016} & \multicolumn{2}{|c|}{ IP 1989 a 2016} & \multicolumn{2}{|c|}{ IMA 1989-2016 } & \multicolumn{2}{|c|}{ IMA* 1989-2004 } \\
\hline & EES & FPC & EES & FPC & EES & FPC & EES & FPC & EES & FPC & EES & FPC \\
\hline CR & 6,88 & 5,86 & 0 & 0 & 6,67 & 5,43 & 6,67 & 5,43 & 0,25 & 0,20 & 0,28 & 0,26 \\
\hline CRDQ & 9,24 & 4,98 & 0 & 0 & 7,16 & 6,11 & 7,16 & 6,11 & 0,26 & 0,23 & 0,27 & 0,30 \\
\hline CRQ & 6,28 & 3,48 & 0 & 0 & 6,36 & 3,83 & 6,36 & 3,83 & 0,23 & 0,14 & 0,29 & 0,15 \\
\hline $\mathrm{CS}_{+8}$ & 8,15 & 5,28 & $1,75^{*}$ & $1,95^{*}$ & 12,14 & 7,01 & 10,39 & 5,06 & 0,38 & 0,19 & 0,33 & 0,29 \\
\hline
\end{tabular}

*Obtido a partir de dados de Araújo; Silva (2010)

Em ambas as áreas, A. pyrifolium parece demonstrar não apresentar condições de regenerar-se, seja por germinação do banco de sementes ou rebrota de cepas, diante de intervenções que utilize da combinação da destoca com a queima. Quanto a este aspecto, Sampaio et al. (1998) afirmam, ao avaliarem o efeito do corte e da queima em espécies da Caatinga em Serra Talhada-PE, que após dois e seis anos das intervenções, entre as espécies que não foram mais registradas após as intervenções encontrava-se $A$. pyrifolium.

Nesse sentido, Griscom; Ashtom (2011) asseveram que, no tocante ao uso do fogo nas florestas tropicais secas, o fogo tem a capacidade de imputar mudanças aos processos sucessionais, favorecendo espécies tolerantes e contribuindo para a existência de dificuldades na regeneração das intolerantes. Ceccon et al. (2006) afirmam que, nas florestas tropicais secas, estudos recentes relataram que a grande frequência dos incêndios e sua alta intensidade reduzem a capacidade de rebrota.

Adicionalmente, Kennard et al., (2002) ao avaliarem o efeito de diferentes intensidades de queima constataram que as queimas de baixa e alta intensidade reduziram, respectivamente, a densidade de sementes viáveis em $50 \%$ e $94 \%$.

Nas duas localidades, as espécies com maior número de indivíduos e fustes são aquelas reconhecidas como pioneiras em áreas do bioma Caatinga que foram submetidas a alterações ambientais, tais como $P$. pyramidalis, M. tenuiflora e $C$. blanchetianus. Tais espécies possuem a capacidade de colonizar áreas com condições ambientais mais severas, em função do maior grau de pioneirismo e por serem mais especializadas a habitar estágios iniciais de sucessão.

Quanto a este aspecto, Araújo; Silva (2010), ao avaliarem dados de medições realizadas em 2004, utilizando os mesmos sistemas silviculturais e mesmas áreas, afirmam que houve aumento da abundância das espécies $P$. pyramidalis e $M$. tenuiflora após os experimentos, em todos os sistemas silviculturais.

Contudo, a partir deste trabalho pode-se averiguar que o comportamento das referidas espécies variou conforme a área. Enquanto na Estação Ecológica do Seridó, P. pyramidalis foi a responsável por $55 \%$ do número de fustes amostrados, na Fazenda Pedro Cândido, ela correspondeu a 10\%. Por outro lado, $M$. tenuiflora representou $25 \%$ do total na Fazenda Pedro Cândido, enquanto apenas $6,9 \%$ dos indivíduos pertenciam a esta espécie na Estação Ecológica do Seridó.

A variação no número de indivíduos entre as áreas, especialmente das espécies $P$. pyramidalis, $M$. tenuiflora e $C$. leptophloeos pode estar relacionada ao modo de ocupação do solo nos locais avaliados e aos atributos químicos do solo $\mathrm{pH}$ e Na. Contudo, a inexistência de registros anteriores, em relação aos atributos químicos do solo, impede inferir se a diferença já existia antes das intervenções, não podendo, portanto, ser atribuída unicamente ao efeito dos sistemas silviculturais.

No tocante à possível interferência do pastejo, podemos levar em consideração as ponderações de Griscom; Ashton (2011), para os quais presença do gado nas florestas tropicais secas da América Central atuou como um agente de seleção natural, favorecendo as espécies não palatáveis e que possuem a capacidade resistir ao pisoteio, enquanto para a maior parte, o gado afetou negativamente o crescimento e sobrevivência das plântulas de árvores pelo pisoteio e a busca entre as plântulas de árvores, reduzindo, dessa forma, a diversidade e a abundância da regeneração natural.

Nesse sentido, o pastejo de gado bovino pode ser um fator impeditivo à regeneração de $P$. pyramidalis e C. leptophloeos, enquanto que favorece $M$. tenuiflor na Fazenda Pedro Cândido. A redução do número de indivíduos de $A$. pyrifolium da Estação Ecológica do Serido em relação à Fazenda Pedro Cândido pode não estar relacionada necessariamente ao uso, mas a condições do solo e à competição interespecífica das espécies na Estação Ecológica do Seridó ou da persistência de condições ambientais que refletem uma maior degradação na Fazenda Pedro Cândido. Essa mesma explicação pode, adicionalmente ao ressaltado anteriormente, ser atribuída ao predomínio de $M$. tenuiflora na Fazenda Pedro Cândido.

A redução da riqueza observada, em relação ao ano de 2004, pode ter ocorrido em função da estiagem que ocorreu na região a partir do ano de 2012, uma vez que as espécies ausentes no presente estudo apresentavam pequeno número de indivíduos nos levantamentos realizados em 2004.

Em relação a outras pesquisas realizadas em ambientes de Caatinga, vê-se que a riqueza registrada nos sistemas silviculturais localizados na EES foi semelhante. É o caso de Marangon et al. (2013) que, avaliando uma área de Caatinga hiperxerófila arbóreo-arbustiva, com área basal de 4,53 $\mathrm{m}^{2}$.ha ${ }^{1}$ e DAP médio de $4 \mathrm{~cm}$, com histórico de perturbação de exploração madeireira e pastejo de caprinos, no município de Floresta - PE, amostrou 18 espécies, 15 gêneros e seis famílias (critério de inclusão - CI: CAP $\geq 6 \mathrm{~cm}$; área amostrada - AA: $\left.8000 \mathrm{~m}^{2}\right)$.

A riqueza de espécies registrada nas parcelas dos sistemas silviculturais localizadas na Estação Ecológica do Seridó se assemelham ao valor registrado por Amorim et al. (2005), ao amostraram uma área sem intervenções na própria Estação Ecológica, em local preservado desde a instalação da unidade 
de conservação, cujo inventário registrou a presença de 15 espécies, 15 gêneros e 10 famílias. Contudo, a riqueza de espécies foi inferior ao registrado por Santana; Souto (2006), que, ao amostrarem também área sem intervenções na Estação Ecológica do Seridó, constataram a presença de 22 espécies, 20 gêneros e 12 famílias.

Uma das explicações para a diferença entre os resultados de levantamentos na própria Estação Ecológica do Seridó é a utilização de critérios de inclusão diferentes, além de não ser ter registrado nos levantamentos do presente estudo espécies de hábito arbustivo que não servisse para a produção de lenha, em vista do objetivo dos experimentos ser monitorar a regeneração da vegetação para a produção deste tipo de produto florestal.

Um valor superior ao número constatado nas parcelas onde se utilizou corte raso neste estudo foi apresentado por Ferraz et al. (2014) que, ao avaliarem uma área submetida a corte raso no município de Floresta-PE, em regeneração há 22 anos, utilizando os mesmos critérios de inclusão deste estudo, registraram a presença de 24 espécies e 19 gêneros.

Contudo, acrescenta-se que a realização da destoca e a queima do restolho da colheita podem ser um impeditivo à regeneração a partir de cepas, que é um importante mecanismo de regeneração em áreas submetidas a intervenções, além da queima ocasionar a redução do banco de sementes do solo, tornando a regeneração dependente de sementes de áreas circunvizinhas, o que pode tornar o processo sucessional mais demorado.

Nesse sentido, Lucena et al. (2016) afirmam que fatores que interfiram sobre a chegada de sementes ao solo exercem significativa influência na regeneração das áreas submetidas a intervenções antrópicas e que, diante de novas ou recrudescimento das intervenções, a brotação a partir de cepas pode ser uma importante estratégia de regeneração, uma vez que as ações antrópicas podem ocasionar, além da destruição do banco de sementes, a eliminação de árvores matrizes.

Quanto a este aspecto, Kennard et al. (2002) afirmam que a rebrota a partir de estruturas vegetativas é um mecanismo de resiliência importante em ambientes de florestas tropicais secas, tendo em vista a comum limitação na umidade do solo. Destarte, o sistema radicular das cepas deixadas no solo após as intervenções proporcionam maior área de superfície de raízes para absorção de água, podendo alcançar umidade e nutrientes em camadas mais profundas do solo, aumentando as chances de regeneração.

Esses autores afirmam que a forma de regeneração predominante (brotação, germinação de banco de sementes ou a chuva de sementes) pode influenciar o sucesso ou a dominâncias de espécies na sucessão. Consequentemente, mudanças na composição de espécies após os distúrbios podem surgir de diferenças nos modos específicos de persistências às perturbações que as espécies apresentam.

Apesar de se cogitar da influência dos sistemas silviculturais sobre a riqueza de espécies, é preciso levar em consideração que outros levantamentos realizados na Região Seridó do Rio Grande do Norte e Paraíba têm demonstrado número de espécies semelhantes aos registrados neste trabalho (AMORIM et al., 2005; SANTANA; SOUTO, 2006; FABRICANTE; ANDRADE, 2007). A baixa riqueza constatada nesta região, comparada com outras regiões do bioma Caatinga, motivou Amorim et al. (2005) a afirmarem que as formações vegetais arbóreo-arbustivas da Caatinga do
Seridó seriam uma tipologia distinta das demais da Caatinga, caracterizada por ser de baixa riqueza de espécies, com menor porte em altura e diâmetro e com menor produção de biomassa.

Contudo, quanto a este aspecto, é preciso ponderar que, em sua maioria, tais levantamentos foram realizados em áreas em sucessão secundária, submetidas aos mesmos usos das do presente estudo. Por essas razões, Griscom; Ashton (2011) afirmam que apesar da capacidade das florestas tropicais secas possuírem de regenerar-se, seja por rebrota e pelo fornecimento de sementes através de árvores remanescentes, em sítios com longa história de desmatamento das terras, a riqueza e a diversidade de espécies poderá permanecer baixa, com grupos funcionais de espécies em falta, a menos que haja um gerenciamento ativo para a condução da regeneração.

No que diz respeito à redução na riqueza espécies em todos os sistemas silviculturais em relação aos levantamentos de 2004, Sampaio et al. (1998), em situação semelhante, afirmam ter constatado maior riqueza de espécies arbustivo-arbóreas nos primeiros anos após o experimento com corte e queima em Serra Talhada-PE, tendo o número reduzido com o passar do tempo.

No tocante à diversidade, contrastando-se os resultados obtidos no presente estudo com aqueles observados em 2004, vê-se que nas duas áreas os valores de $\mathrm{H}^{\prime}$ diminuíram para todos os sistemas silviculturais, com exceção do CR e CRQ na Fazenda Pedro Cândido. Os maiores valores apresentados por eles, estão, provavelmente, relacionados à melhor distribuição do número de indivíduos entre as espécies amostradas. $\mathrm{Na}$ Estação Ecológica do Seridó, apesar de o CRDQ ter apresentado número de espécies semelhante ao $\mathrm{CS}_{+8}$, a grande abundância de indivíduos de $P$. pyramidalis e C. blanchetianus contribuiu para o menor valor de H'. Na Fazenda Pedro Cândido, apesar de o CR não ter apresentado o maior número de espécies, uma distribuição mais equitativa do número de indivíduos entre as espécies amostradas contribuiu para o maior valor de $\mathrm{H}^{\prime}$ registrado.

Apesar de não ter havido, em ambas as áreas, efeito estatístico dos sistemas silviculturais sobre os valores de J', em ambos os locais o $\mathrm{CS}_{+8}$ apresentou os maiores valores, com o CRDQ tendo demonstrado a menor equabilidade de espécies. Contudo, observou-se, com base nos dados de 2004 (ARAÚJO; SILVA, 2010), que, na Fazenda Pedro Cândido, o ritmo de aparecimento de novas espécies foi mais lento que na Estação Ecológica do Seridó e que por este motivo, aquela se mostrou mais susceptível a apresentar menor diversidade.

Estes mesmos autores mostraram que, em relação à situação antes das intervenções (1989), os valores de H' eram maiores nas parcelas presentes na EES. Em 2004, o índice de diversidade Shannon-Weaver tendeu a diminuir na Estação Ecológica do Seridó, enquanto na Fazenda Pedro Cândido o índice aumentou nos $\mathrm{CR}_{\text {e }} \mathrm{CS}_{+8}$ e diminuiu nos CRDQ e CRQ. No presente trabalho, observou-se que, com exceção do CR, todos os sistemas silviculturais apresentaram maior diversidade na EES, tendo em ambos os casos o CRDQ proporcionado as menores diversidades.

Relativamente às mudanças que as intervenções causam sobre a sucessão, Chazdon (2012) afirma que após distúrbios, os processos sucessionais levam a alterações na composição de espécies, tamanho e estrutura das populações que formam as comunidades florestais, de modo que as trajetórias sucessionais variam amplamente, conforme a natureza do uso 
anterior da terra, da proximidade de outros fragmentos e disponibilidade de mecanismos de dispersão.

O menor valor registrado de H' para o CRDQ é motivado pela grande abundância de $M$. tenuiflora e C. blanchetianus, as quais foram responsáveis por $80 \%$ dos indivíduos registrados nas quatro parcelas deste sistema silvicultural, o que é corroborado pelo índice de equabilidade de Pielou.

Tratando-se da estrutura horizontal, vê-se que, na Fazenda Pedro Cândido, semelhantemente à Estação Ecológica do Seridó, $\quad \mathrm{o} \quad \mathrm{CS}_{+8}$ e $\mathrm{o}$ CRDQ apresentaram as maiores dominâncias absolutas, porém com valores menores em relação à Estação Ecológica.

Na FPC, a superioridade do $\mathrm{CS}_{+8}$ se deu em função de $P$. pyramidalis que, apesar de ter tido a metade da densidade relativa de $A$. pyrifolium, apresentou maior dominância relativa. $M$. tenuiflora apesar de não ter tido as maiores densidades nos CR e CRQ, teve os maiores valores de dominância absoluta. No CRDQ, M. tenuiflora foi dominante, tanto em termos de densidade quanto de dominância absoluta.

Ferraz et al. (2014) também constataram que uma espécie do gênero Poincianella ( $P$. bracteosa) foi a que apresentou o maior valor de importância $(37,18 \%)$ em uma localidade que fora submetida a corte raso há 22 , mas em regeneração. Especificamente no que diz respeito à contribuição de $P$. pyramidalis, Santana et al. (2011), ao avaliarem todos os indivíduos vivos da referida espécie em locais sem as intervenções silviculturais utilizadas neste estudo na Estação Ecológica do Seridó, constataram que ela se destacou como a mais importante para este local, com uma densidade de 675 ind.ha- ${ }^{-1}$ e dominância absoluta de $4,65 \mathrm{~m}^{2} \cdot \mathrm{ha}^{-1}$. Para eles, a elevada população dessa espécie pode ser resultado do grau de atividade antrópica ocorrente antes da área ser convertida em unidade de conservação.

Com relação a uma das mais importantes espécies na FPC, Holanda et al. (2015) ao estudarem a estrutura da vegetação em dois ambientes com diferentes históricos de uso no município de Cajazeirinhas-PB, registraram que no local mais degradado (ambiente I), Mimosa tenuiflora foi a espécie de maior importância, mas com $85 \%$ do valor registrado. Os autores justificam esses resultados em função desta espécie, teoricamente, explorar melhor os recursos propiciados pelo habitat em condições iniciais de sucessão ecológica.

Neste estudo, constata-se que nas duas localidades, do ponto de vista do manejo florestal, no sentido do aproveitamento econômico das espécies e tendo em vista a sustentabilidade e conservação ambiental, há um pequeno espectro de espécies aproveitáveis, em função principalmente da baixa densidade e dominância absoluta.

Relativamente à dinâmica da dominância absoluta, Meunier; Carvalho (2000) ao avaliarem a dinâmica do crescimento destes mesmos sistemas silviculturais, em levantamentos realizados a partir de 1995, haviam constatado um IMA médio de $0,45 \mathrm{~m}^{2} \mathrm{ha}^{-1} \mathrm{ano}^{-1}$, o que levaria a um ciclo de corte de poucos mais 15 anos, considerando uma área basal média de $7 \mathrm{~m}^{2} \mathrm{ha}^{-1}$.

Vê-se, portanto, que no início do processo de regeneração há um maior acúmulo de biomassa, traduzido pelo aumento nos diâmetros dos fustes dos indivíduos, contudo, reduzindose com o decorrer da sucessão. Inicialmente, isto remete ao fato de não ser aconselhável traçar ciclos de corte com base em dados coletados no início do processo de regeneração.

De modo similar a esta pesquisa, Ferraz et al. (2014) registraram um incremento médio anual de $0,1113 \mathrm{~m}^{2} \mathrm{ha}^{-1}$ ao avaliarem uma área submetida a corte raso em Floresta-PE, após 22 anos de regeneração natural. Eles asseveram que, considerando a área basal registrada em um local conservado (contínguo à área avaliada), seria necessário um período de 40,9 para a equiparação dos valores.

Em relação a outros trabalhos em ecossistemas da Caatinga, os dados de dominância absoluta registrados nesta pesquisa estão de acordo com os levantamentos de alguns autores (AMORIM et al., 2005; COSTA et al., 2009; CALIXTO JÚNIOR; DRUMOND, 2011; MARANGON et al., 2013).

Contudo, Andrade et al. (2007) afirmam que a variação de dominância absoluta entre diferentes levantamentos reflete as características das diferentes fisionomias do bioma Caatinga, as variações biofísicas e os diferentes graus de impactos provocados por ações antrópicas incidentes sobre as áreas avaliadas. Ademais, Santana; Souto (2006) ainda atentam para o fato de se utilizarem diferentes métodos e critérios de inclusão de diâmetros e de parâmetros para admissão de espécies, relativamente ao hábito das espécies, pois um pesquisador pode considerar determinada espécie como arbustiva e não incluí-la no levantamento.

Além de características locais, é preciso considerar que nas áreas que sofreram alguma modalidade de intervenção, a exemplo de corte, queima e destoca, cujas operações podem ou não serem consorciadas com o pastejo, provavelmente há mais dificuldades para o desenvolvimento de estrutura florestal de maior porte.

Griscom; Ashton (2011) afirmam que o uso de ferramentas de manejo, a exemplo do fogo e pastejo, em florestas tropicais secas, pode inibir a regeneração das espécies intolerantes, favorecendo aquelas resistentes, impondo, dessa forma, mudanças em processos sucessionais. Eles afirmam que é esperado que a regeneração nessas florestas, quando submetidas ao fogo, seja mais lenta. Além desse fator, eles destacam que a ação do gado como agente de seleção natural favorece espécies que não são palatáveis, ou ainda aquelas que resistem ao pisoteio.

\section{CONCLUSÕES}

A riqueza de espécies apresenta condições semelhantes às da época da instalação do experimento. A grande abundância de algumas espécies contribuiu para a redução da diversidade medida pelo índice de Shannon-Weaver, em relação a 1989.

Não houve diferença estatística para a diversidade medida pelo Índice de equabilidade de Pielou (J').

Os incrementos proporcionados pelos sistemas silviculturais variaram conforme a área, porém em ambas com tendência de redução do ritmo de crescimento para essa variável. O tempo de regeneração (27 anos) não foi suficiente para a restauração integral da dominância absoluta.

\section{AGRADECIMENTOS}

À Rede de Manejo Florestal da Caatinga pela disponibilização dos recursos necessários aos trabalhos de campo, referentes às medições e ao Instituto Chico Mendes da Conservação da Biodiversidade (ICMBIO) pela autorização para a realização da pesquisa na Estação Ecológica do Seridó.

\section{REFERÊNCIAS}

AMORIM, I. L.; SAMPAIO, E. V. S. B.; ARAÚJO, E. L. Flora e estrutura da vegetação arbustivo-arbórea de uma área de caatinga do Seridó, RN, Brasil. Acta Botanica 
Brasilica, Belo Horizonte, v. 19, n. 3, p. 615-623, 2005. Disponível

em:

$<$ http://www.scielo.br/pdf/abb/v19n3/27377.pdf $>$ Acesso em: 05 de Nov de 2013

ANDRADE, L. A.; OLIVEIRA, F. X.; NEVES, C. M. L.; FELIX, L. P. Análise da vegetação sucessional em campos abandonados no agreste paraibano. Revista Brasileira de Ciências Agrárias, Recife, v. 2, n. 2, p. 135-142, 2007. Disponível em: $<$ http://www.agraria.pro.br/sistema/index.php?journal=ag raria\&page $=$ article \&op $=$ view $\&$ path $\% 5 \mathrm{~B} \% 5 \mathrm{D}=174 \&$ path $\% 5 \mathrm{~B} \% 5 \mathrm{D}=81>$ Acesso em: 12 de Out 2013 .

ARAÚJO, L. V. C.; SILVA, J. A. Unidade experimental estação ecológica do Seridó-RN. In: GARIGLIO, et al. Uso sustentável e conservação dos Recursos Florestais da Caatinga. Brasília: Serviço Florestal Brasileiro, 2010. Disponível em: $<$ http://www.mma.gov.br/estruturas/sfb/arquivos/web_u so_sustentvel_e_conservao_dos_recursos_florestais_da_c aatinga_95.pdf $>$ Acesso em: 19 de Mar de 2014.

BROWER, J. E.; ZAR, J. H. Field and laboratory methods for general ecology. 2. ed. Dubuque: Wm, C. Brown Publishers, 1984. $226 \mathrm{p}$.

CALIXTO JÚNIOR, J. T.; DRUMOND, M. A. Estrutura Fitossociológica de um fragmento de Caatinga Sensu Stricto 30 anos após corte raso, Petrolina-PE, Brasil. Revista Caatinga, Mossoró, v. 24, n. 2, p. 67-74, 2011. Disponível

http://periodicos.ufersa.edu.br/revistas/index.php/sistema/ article/view/1917/4714> Acesso em: 14 de Abril de 2014.

CECCON, E.; HUANTE, P.; RINCÓN, E. Abiotic Factors influencing tropical dry forests regeneration. Brazilian Archives of Biology and Technology, Curitiba, v. 49, n. 2, p. 305-312, 2006. DOI: http://dx.doi.org/10.1590/S1516-89132006000300016

CHAZDON, R. Regeneração de florestas tropicais. Revista Ciências Naturais, Belém, v. 7, n. 3, p. 195-218, 2012. Disponível em: $<$ http://www.museugoeldi.br/editora/bn/artigos/cnv7n3_2 012/regeneracao(chazdon).pdf $>$ Acesso em: 28 de Jan de 2014.

COSTA, T. C. C.; OLIVEIRA, M. A. J.; ACCIOLY, L. J. O.; SILVA, F. H. B. B. Análise da degradação da Caatinga no núcleo de desertificação do Seridó (RN/PB). Revista Brasileira de Engenharia Agrícola e Ambiental. Campina Grande, v. 13, p. 961-974, 2009. Disponível em: $<$ http://www.scielo.br/pdf/rbeaa/v13s0/v13s0a20.pdf $>$ Acesso em: 03 de Out de 2013.

EMBRAPA - EMPRESA BRASILEIRA DE PESQUISA AGROPECUÁRIA . Manual de métodos de análise de solos. Rio de Janeiro: Centro Nacional de Pesquisa de Solos, $1997.212 p$ $<$ http://www.agencia.cnptia.embrapa.br/Repositorio/Man ual+de+Metodos_000fzvhotqk02wx5ok0q43a0ram31wtr. pdf> Acesso em: 09 de Mai de 2015.

EMBRAPA - EMPRESA BRASILEIRA DE PESQUISA AGROPECUÁRIA. Sistema brasileiro de classificação de solos. 3. ed. Brasília: Embrapa, 2013. 353p.

FABRICANTE, J. R.; ANDRADE, L. A. Análise estrutural de um remanescente de Caatinga no Seridó Paraibano. Oecologia brasiliensis, Rio de Janeiro, v. 11, n.3 , p. 341349, 2007. Disponível em:
$<$ http://www.ppgecologia.biologia.ufrj.br/oecologia/index .php/oecologiabrasiliensis/article/view/149/115> Acesso em: 19 de Dez de 2013.

FERRAZ, J. S. F.; FERREIRA, R. L. C.; SILVA, J. A. A.; MEUNIER, I. M. J.; SANTOS, M. V. F. Estrutura do componente arbustivo-arbóreo da vegetação em duas áreas de Caatinga, no município de Floresta-PE. Revista Árvore, Viçosa, v. 38, n. 6, p. 1055-1064, 2014. DOI: http://dx.doi.org/10.1590/S0100-67622014000600010.

FLORA DO BRASIL. (2017). Lista de espécies da Flora do Brasil. Jardim Botânico do Rio de Janeiro. Disponível em: http://floradobrasil.jbrj.gov.br/

GRISCOM, H. P.; ASHTON, M. S. Restoration of dry tropical forests in Central America: A review of pattern and process. Forest Ecology and Management, v. 226, n. 10, p. 1564-1579, 2011. DOI: https://doi.org/10.1016/j.foreco.2010.08.027

HOLANDA, A. C.; LIMA, F. T. D.; SILVA, B. M.; DOURADO, R. G.; ALVES, A. R. Estrutura da vegetação em remanescente de Caatinga com diferentes históricos de perturbação em Cajazerinhas (PB). Revista Caatinga, Mossoró, v. 28, n. 4, p. 142-150, 2015. DOI: http://dx.doi.org/10.1590/1983-21252015v28n416rc

IBGE - INSTITUTO BRASILEIRO DE GEOGRAFIA E ESTATÍSTICA. Produção da Extração Vegetal e da Silvicultura - ano 2016. Rio de Janeiro, 2017. Disponível em: < https://sidra.ibge.gov.br/tabela/289\#resultado> Acesso em: 15 de Mai. de 2017.

KENNARD, D. K.; GOULD, K.; PUTZ, F. E.; FREDERICKSEN, T. S.; MORALES, F. Effect of disturbance intensity on regeneration mechanisms in a tropical dry forest. Forest ecology and Management, Amsterdam, v. 162, p. 197-208, 2002. Disponível em: DOI: https://doi.org/10.1016/S0378-1127(01)00506-0 Acesso em: 05 de Mai de 2015.

KÖPPEN, W. Tradução: CORRÊA, A. C. B. Sistema Geográfico dos Climas. Notas e Comunicado de Geografia - Série B: Textos Didáticos $n^{\circ} 13$. Editora Universitária - UFPE, Departamento de Ciências Geográficas, UFPE, p.31, 1996.

LUCENA, M. S.; SILVA, J. A.; ALVES, A. R. Regeneração natural do estrato arbustivo-arbóreo em área de Caatinga na Estação Ecológica do Seridó - RN, Brasil. Revista Biotemas, Florianópolis, v. 29, n. 2, p. 17-31, 2016. DOI: http://dx.doi.org/10.5007/2175-7925.2016v29n2p17 Acesso em: 11 de Mai. de 2016

MARANGON, G. P.; FERREIRA, R. L. C.; SILVA, J. A.; LIRA, D. F. S.; SILVA, E. A.; LOUREIRO, G. H. Estrutura e padrão espacial da vegetação em uma área de Caatinga. Floresta, Curitiba, v. 43, n. 1, p.83-92, 2013. DOI: http://dx.doi.org/10.5380/rf.v43i1.27807

Acesso em: 09 de Dez. de 2016

MATTOS, P. P.; BRAZ, E. M.; DOMENE, V. D.; SAMPAIO, E. V. S.; GASSON, PETER.; PAREYN, F. G. C.; ALVAREZ, I. A.; BARACAT, A.; ARAÚJO, E. L. Climate-tree growth relationships of Mimosa tenuiflora in seasonally dry tropical forest, Brazil. Cerne, v.21, n.1, p.141-149, 2015.2 DOI: http://dx.doi.org/10.1590/01047760201521011460 Acesso em: 23 de Jan. de 2018

MEUNIER, I. M. J.; CARVALHO, J. E. Crescimento da caatinga submetida a diferentes tipos de corte, na 
Região do Seridó do Rio Grande do Norte. Natal: Projeto MMA/FAO/UTF/BRA/047, 2000. 28 p. (Boletim Técnico; n.4).

MUELLER-DAMBOIS, D.; ELLEMBERG, H. Aims and methods of vegetation ecology. New York: Jonh Willey y Sons, 1974. 547p.

QUESADA, M.; SANCHEZ-AZOFEIFA, G. A.; ALVAREZANORVE, M.; STONER, K. E.; AVILA-CABADILLA, L.; CALVO-ALVARADO, J.; CASTILLO, A.; ESPÍRITO-SANTO, M. M.; FAGUNDES, M.; FERNANDES, G. W.; GAMON, J.; LOPEZARAIZAMIKEL, M.; LAWRENCE, D. MORELATO, L. P. C.; POWERS, J. S.; NEVES, F. S.; ROSAS-GEURRERO, V.; SAYAGO, R.; SANCHEZ-MONTOYA, G. Sucession and manegement of tropical dry forest in the Americas: Review and new perspectives. Forest Ecology and Management, Amsterdam, v. 258, n .6, p. 1014-1024, 2009. DOI: http://dx.doi.org/10.1016/j.foreco.2009.06.023 Acesso em:

RMFC - REDE DE MANEJO FLORESTAL DA CAATINGA. Protocolo de Medições de Parcelas Permanentes. Recife: Associação de Plantas do Nordeste; Brasília: MMA, PNF, PNE, 2005. 30p. Disponível em: $<$ http://www.cnpf.embrapa.br/pesquisa/sispp/protocolo_R MFC.pdf $>$ Acesso em: 27 de Nov. de 2013.

SAMPAIO, E. V. S. B.; ARAÚJO, E. L.; SALCEDO, I. H.; TIESSEN, H. Regeneração da vegetação de caatinga após corte e queima, em Serra Talhada, PE. Revista Pesquisa
Agropecuária Brasileira, Brasília, v. 33, n. 5, p. 621-632, $1998 . \quad$ Disponível em: $<$ http://seer.sct.embrapa.br/index.php/pab/article/view/48 90/7006> Acesso em: 03 de Out de 2013.

SANTANA, J. A. S.; SOUTO, J. S. Diversidade e Estrutura Fitossociológica da Caatinga na Estação Ecológica do Seridó-RN. Revista de Biologia e Ciências da Terra, São Cristóvão, v. 6, n. 2, p. 232-242, 2006. Disponível em: $<$ http://eduep.uepb.edu.br/rbct/sumarios/pdf/serido.pdf $>$ Acesso em: 03 de Out. de 2013.

SANTANA, J. A. S.; VIEIRA, F. A.; PACHECO, M. V.; OLIVEIRA, P. R. S. Padrão de distribuição e estrutura diamétrica de Caesalpinia pyramidalis Tul. (Catingueira) na Caatinga do Seridó. Revista de Biologia e Ciências da Terra, São Cristóvão, v. 11, n. 1, 2011. Disponível em: < http://www.redalyc.org/pdf/500/50021097012.pdf.> Acesso em: 28 de Dez. de 2016.

SOUZA, A. L.; SOARES, C. P. B. Florestas Nativas: estrutura, dinâmica e manejo. Viçosa- MG: Ed. UFV, 2013. $322 \mathrm{p}$

VELAZCO, S. J. E.; GALVÃO, F. KELLER, H. A.; BEDRIJ, N. A. Florística e fitossociologia de uma floresta estacional semidecidual, reserva privada Osununú-Misiones, Argentina. Floresta e Ambiente, v. 22, n. 1, p. 1-12, 2015. DOI: http://dx.doi.org/10.1590/2179-8087.038513 Acesso em: 23 de Jan. de 2018 